\title{
Predictors of recurrence in thymic tumors: Importance of invasion, World Health Organization histology, and size
}

\author{
Cameron D. Wright, MD, John C. Wain, MD, Daniel R. Wong, MD, MPH, Dean M. Donahue, MD, \\ Henning A. Gaissert, MD, Hermes C. Grillo, MD, and Douglas J. Mathisen, MD
}

Objective: This study sought to define predictors of recurrence after resection of thymic tumors.

Methods: A single-institution retrospective study was performed of 179 patients who underwent resection of a thymic tumor from 1972 through 2003.

Results: Resection was complete in $90 \%$ (161/179) of patients. After a median follow-up of 115 months, the recurrence rate was $11 \%$ (20/179), the tumor-related death rate was $7.8 \%(14 / 179)$, and the overall death rate was $36.3 \%(65 / 179)$. Tumor recurrence correlated with advanced stage and histology $(P<.0001)$. The difference in recurrence between Masaoka stage I (0) and II (1.7\% [1/59]) was insignificant. Recurrence rates correlated with World Health Organization tumor type: A and AB, 0\%; B1 and B2, 8\% (4/51); B3, 27\% (14/51); and C, 50\% (2/4; $P<.0001)$. Tumor size separation into quintiles demonstrated a step-up of recurrence at $8 \mathrm{~cm}$ ( $<8 \mathrm{~cm}, 1.8 \%$ [2/113]; $\geq 8 \mathrm{~cm}, 28 \%$ [18/64]; $P<.003)$. Multivariate Cox modeling demonstrated that Masaoka stage (odds ratio, 5.70; $P<.001$ ), World Health Organization histology (odds ratio, 5.77; $P=.003$ ), and size (odds ratio, 1.16; $P=$ .001 ) were independent predictors of recurrence.

Conclusion: The Masaoka staging system could be collapsed to 3 degrees of invasion by combining stages I and II. The World Health Organization histologic type can be simplified for clinical use into A (A, AB), early B (B1, B2), advanced B (B3), and C tumors. Size of $8 \mathrm{~cm}$ or larger is an independent risk factor, even when patients with Masaoka stage III tumors are considered alone, and might identify candidates for preoperative therapy.

From the Division of General Thoracic Surgery, Massachusetts General Hospital, Department of Surgery, Harvard Medical School, Boston, Mass.

Read at the Eighty-fifth Annual Meeting of The American Association for Thoracic Surgery, San Francisco, Calif, April 10-13, 2005.

Received for publication April 4, 2005; revisions received June 27, 2005; accepted for publication July 11, 2005

Address for reprints: Cameron D. Wright, MD, Blake 1570, Massachusetts General Hospital, Boston, MA 02114 (E-mail: wright.Cameron@mgh.harvard.edu).

J Thorac Cardiovasc Surg 2005;130:1413-21 $0022-5223 / \$ 30.00$

Copyright (c) 2005 by The American Association for Thoracic Surgery

doi:10.1016/j.jtcvs.2005.07.026
$\mathrm{P}$ revious reports suggest the best predictors of outcome in thymoma are Masaoka stage (a surrogate marker for the biologic aggressiveness of the tumor), the World Health Organization (WHO) histologic classification system, and the performance of a complete resection. ${ }^{1-10}$ Some studies report that great vessel invasion and larger size also predict a poor prognosis. ${ }^{3,4,6,7}$ Older reports of risk factors must be judged with caution because of inadequate statistical evaluation, lack of prolonged follow-up ( $>10$ years' follow-up is needed to evaluate for possible recurrence), and use of overall survival rather than the more accurate thymoma-related survival. Although the Masaoka staging system is the most commonly used, several other schemes have been proposed and used. ${ }^{11,12}$ Several groups have reported on the lack of any significant difference between Masaoka stages I and II. ${ }^{2}$ Indeed, the original report by Masaoka did not demonstrate any difference between stages I and II. ${ }^{13}$ Several groups have proposed consideration of both Masaoka stage and WHO histology in estimating prognosis because either is an independent predictor of recurrence and death from thymoma. ${ }^{1,2,5-7,9,10}$ With a relatively large database of patients with thymoma, we sought to define the best discriminators of prognosis and how they might be used in a staging system. We 


\section{Abbreviations and Acronyms \\ $\mathrm{CI}=$ confidence interval \\ $\mathrm{OR}=$ odds ratio \\ WHO $=$ World Health Organization}

sought to investigate the effect of size on prognosis because it would be readily available to the clinician at the time of diagnosis and thus could guide preoperative therapy. Furthermore, we decided to emphasize recurrences over deaths because death is not inevitable if there is a recurrence, and recurrence might precede death by many years. Selecting recurrence rather than death also improves modeling because more events are analyzed.

\section{Patients and Methods}

From 1972 through 2003, 179 patients underwent transsternal resection of a thymic tumor (thymoma or thymic carcinoma) at the Massachusetts General Hospital. Five patients who underwent exploration or debulking only in the same time period were excluded. Resection encompassed the tumor, the entire thymus, the mediastinal fat from one phrenic nerve to the other, and all invaded adjacent structures. Eight patients with difficult-to-resect tumors had induction therapy: 5 had radiation alone (30-45 Gy), 1 had chemotherapy alone (cisplatin and etoposide), and 2 had chemoradotherapy (45 Gy, cisplatin and etoposide). Postoperative radiation ( $n=69$ patients) was given for close or positive margins and at the discretion of the radiation oncologist for invasive tumors (50-60 Gy). A database of patients with thymoma has been maintained at the Massachusetts General Hospital since the first report in 1970. Some of these patients form the basis of previous reports. ${ }^{2}$ Data from patient records were abstracted and recorded as variables, as seen in Table 1. Survival and recurrence information has been collected through patient or relative contact, contact with personal physicians, and examination of death records. Median follow-up was 115 months, follow-up has been completed in $96 \%$ of patients, and only 6 patients were lost to follow-up at 2, 3, 6, 78, 80 , and 120 months, respectively. Approval for this study was granted by the institutional review board.

Comparison between groups of categoric variables were made by using the $\chi^{2}$ statistic. The Kaplan-Meier method was used to estimate the disease-free survival, thymoma-related survival, and overall survival. The log-rank test was used to compare survival of different groups. The Cox proportional hazards regression model was used to determine prognostic variables. Logistic regression was used to model binary outcomes. Multivariable models with stepwise entry criteria ( 0.10 to enter and 0.05 to retain) with manual oversight were constructed by using both proportional hazards and logistic regression analysis for selected variables, with univariable significance at the $P<.10$ level. Receiver operating characteristic curves were generated for logistic models, and the c-statistic was calculated. The Hosmer-Lemeshow test was calculated for the final models. Bootstrap analysis $(n=1000)$ was used to test the validity of the model.

\section{Results}

Patient characteristics are listed in Table 1. There were 59 Masaoka stage 2 tumors: 40 with macroscopic invasion and 19 with microscopic invasion of the capsule. There were 45 Masaoka stage 3 tumors: 43 invaded the pleura, 14 invaded the great vessels, 37 invaded the pericardium, and 25 invaded the lung. There were 11 Masaoka stage 4 tumors: 11 had pleural metastases, and 2 had pericardial metastases. Two patients died after resection ( 1 of stroke and 1 of pulmonary embolism). Complete resection were performed in $90 \%(161 / 179)$ of patients. Ten-year thymoma-related survival was $92 \%$ (95\% confidence interval [CI], 88\%$97 \%)$, whereas 10 -year overall survival was only $71 \%(95 \%$ CI, 64\%-79\%). Fourteen patients died of persistence or recurrence of the thymoma, which represented only $22 \%$ (14/65) of late deaths. Ten-year disease-free survival was $87 \%$ (95\% CI, 82\%-93\%). Twenty (11\%) of 179 patients had a recurrence: pleural implants, 16; mediastinal, 2; and distant, 2. Sixty percent (12/20) of recurrences were within 5 years, and $40 \%(8 / 20)$ were beyond 5 years.

Table 1 summarizes the results of the univariable analysis of prognostic factors on recurrence and thymoma death rates. The invasion variables (pleural, lung, pericardial, or great vessel invasion) were studied, and all were highly correlated (all $P<.0001$ ). All invasion variables were associated with recurrence and death. No individual invasion parameter stood out as a better predictor of recurrence or death. WHO histology was also highly correlated with Masaoka stage $(P<.0001)$. Tumor size was highly correlated with stage $(P<.0001)$, histology $(P=.015)$, and complete resection $(P=.009)$. Increasing size was associated with recurrence and death. When size was divided into quintiles, there was a clear step-up in recurrences at $8 \mathrm{~cm}$ $(P<.003)$ by means of logistic regression analysis (Table 2 ). This threshold of tumor size was also seen on a timeto-event analysis, with a wide separation at $8 \mathrm{~cm}$ (Figure 1). Tumors of $8 \mathrm{~cm}$ or larger were more likely to be Masaoka stage III or IV (35/56 [62.5\%] of all stage III or IV tumors) than Masaoka stage I or II (29/121 [23.9\%] of all stage I or II tumors; $P<.0001)$. Tumors of $8 \mathrm{~cm}$ or larger were more likely to be WHO type B1 or greater (46/105 [43.8\%] of all $\mathrm{B} 1$ or greater tumors) than $\mathrm{A}$ or $\mathrm{AB}$ (18/72 [25\%] of all A or AB tumors; $P=.035)$. Masaoka stage stratified recurrence relatively well $(P<.0001$, Figure 2$)$. There was no difference in recurrence between stages I and II or between stages IIa and IIb. There was a large step-up in risk between stages I and II and the later 2 stages (Table 3 ). WHO type $\mathrm{A}$ and $\mathrm{AB}$ tumors acted in a benign fashion, with no recurrences or deaths (Figure 3 and Table 4). WHO type B tumors did recur, especially B3 tumors. B1 and B2 tumors had an $8 \%$ (4/51) recurrence rate, which was in contrast to B3 tumors with a $27 \%(14 / 51)$ recurrence rate. Type C tumors had a $50 \%(2 / 4)$ recurrence rate. 
TABLE 1. Patient characteristics and univariable analysis of prognostic factors

\begin{tabular}{|c|c|c|c|c|c|c|c|}
\hline Variable & $\begin{array}{c}\text { Overall } \\
(n=179)\end{array}$ & $\begin{array}{l}\text { No recurrence } \\
(n=159)\end{array}$ & $\begin{array}{c}\text { Recurrence } \\
(\mathrm{n}=20)\end{array}$ & $P$ value & $\begin{array}{l}\text { Thymoma death } \\
(\mathrm{n}=14)\end{array}$ & $\begin{array}{l}\text { No thymoma death } \\
(n=165)\end{array}$ & $P$ value \\
\hline \multicolumn{8}{|l|}{ Age } \\
\hline$\geq 40$ & 150 (83.8) & 137 (86.2) & $13(65.0)$ & .03 & 140 (84.8) & $10(71.4)$ & .46 \\
\hline$\geq 50$ & $129(72.1)$ & $119(74.8)$ & $10(50.0)$ & .07 & $121(73.3)$ & $8(57.1)$ & .52 \\
\hline$\geq 60$ & $84(46.9)$ & 78 (49.1) & $6(30.0)$ & .25 & $80(48.5)$ & $4(28.6)$ & .42 \\
\hline$\geq 70$ & $39(21.8)$ & $37(23.3)$ & $2(10.0)$ & .27 & $38(23.0)$ & $1(7.1)$ & .32 \\
\hline Male sex & $85(47.5)$ & 74 (46.5) & $11(55.0)$ & .59 & $77(46.7)$ & $8(57.1)$ & .53 \\
\hline MG & $53(29.6)$ & $49(30.8)$ & $4(20.0)$ & .18 & $49(29.7)$ & $4(28.6)$ & .58 \\
\hline Other para & $2(1.1)$ & $1(0.6)$ & $1(5.0)$ & $<.0001$ & $1(0.6)$ & $1(7.1)$ & .0007 \\
\hline Symptoms & 98 (54.8) & $82(51.6)$ & $16(80.0)$ & .02 & $86(52.1)$ & 12 (85.7) & .02 \\
\hline Complete & $161(89.9)$ & $150(94.3)$ & $11(55.0)$ & $<.0001$ & $153(92.7)$ & $8(57.1)$ & $<.0001$ \\
\hline \multicolumn{8}{|l|}{ Resection } \\
\hline \multicolumn{8}{|l|}{ Invasion } \\
\hline Pleural & $62(34.6)$ & $43(27.0)$ & $19(95.0)$ & $<.0001$ & $49(29.7)$ & $13(92.9)$ & $<.0001$ \\
\hline Great vessel & $17(9.5)$ & $11(6.9)$ & $6(30.0)$ & .0003 & $11(6.7)$ & $6(42.9)$ & $<.0001$ \\
\hline Pericardial & $47(26.3)$ & $28(17.6)$ & $19(95.0)$ & $<.0001$ & $34(20.6)$ & $13(92.9)$ & $<.0001$ \\
\hline Lung & $34(19.0)$ & $21(13.2)$ & $13(65.0)$ & $<.0001$ & $26(15.8)$ & 8 (57.1) & $<.0001$ \\
\hline \multicolumn{8}{|l|}{ Size } \\
\hline Mean & $7.2 \pm 3.9$ & $6.7 \pm 3.12$ & $11.0 \pm 6.4$ & $.007^{*}$ & $6.8 \pm 3.1$ & $11.8 \pm 7.5$ & $.03^{*}$ \\
\hline Median & 7.0 & 6.0 & 9.5 & $<.0001^{*}$ & 6.0 & 10.0 & $.0002^{*}$ \\
\hline$>5 \mathrm{~cm}$ & $115(65.0)$ & $96(61.2)$ & $19(95.0)$ & .0001 & $102(62.6)$ & $13(92.9)$ & .02 \\
\hline$\geq 8 \mathrm{~cm}$ & $64(35.8)$ & $46(28.9)$ & $18(90.0)$ & $<.0001$ & 52 (31.5) & 12 (85.7) & $<.0001$ \\
\hline$\geq 10 \mathrm{~cm}$ & $37(20.9)$ & 27 (17.2) & $10(50.0)$ & .004 & $29(17.8)$ & 8 (57.1) & $<.0001$ \\
\hline \multicolumn{8}{|l|}{ WHO } \\
\hline A & $21(11.7)$ & $21(13.2)$ & 0 & $<.0001$ & $21(12.7)$ & 0 & $<.0001$ \\
\hline$A B$ & $52(29.0)$ & $52(32.7)$ & 0 & & $52(31.5)$ & 0 & \\
\hline B1 & $27(15.1)$ & $25(15.7)$ & $2(10.0)$ & & $25(15.2)$ & $2(14.3)$ & \\
\hline B2 & $24(13.4)$ & $22(13.8)$ & $2(10.0)$ & & $23(13.9)$ & $1(7.1)$ & \\
\hline B3 & $51(28.5)$ & $37(23.3)$ & $14(70.0)$ & & $42(25.4)$ & $9(64.3)$ & \\
\hline C & $4(2.2)$ & $2(1.3)$ & $2(10.0)$ & & $2(1.2)$ & 2 (14.3) & \\
\hline \multicolumn{8}{|l|}{ Masaoka } \\
\hline I & $64(35.8)$ & $64(40.2)$ & 0 & $<.0001$ & $64(38.8)$ & 0 & $<.0001$ \\
\hline II & $59(33.0)$ & $58(36.5)$ & $1(5.0)$ & & $58(35.2)$ & $1(7.1)$ & \\
\hline III & $45(25.1)$ & 31 (19.5) & $14(70.0)$ & & 35 (21.2) & $10(71.4)$ & \\
\hline IV & $11(6.2)$ & $6(3.8)$ & $5(25.0)$ & & 8 (72.7) & $3(21.4)$ & \\
\hline
\end{tabular}

This table lists the recurrence rate and thymoma death rate for various potential prognostic factors. $P$ values were obtained by using the log-rank test unless otherwise specified $\left({ }^{*} t\right.$ test or Wilcoxon rank sum test). $M G$, Myasthenia gravis; Other para, other paraneoplastic syndromes.

Multivariable models were constructed to predict recurrence. Cox proportional hazards analysis indicated that Masaoka stage (odds ratio [OR], 5.70; $P<.0001$ ), WHO histology (OR, 5.77; $P=.003$ ), and size (OR, 1.16; $P=$ $.001)$ were independent predictors. The results of the mul- tivariable logistic model were quite similar, with the same variables identified as significant (data not shown). When this model was restricted to patients with Masaoka stage III tumors only, size of $8 \mathrm{~cm}$ or larger remained a good predictor of recurrence $(\mathrm{OR}, 13.9 ; P=.02)$. Receiver operating

TABLE 2. Recurrence rate as a function of size

\begin{tabular}{|c|c|c|c|c|c|}
\hline Size quintiles: & $1(1.0-4.0 \mathrm{~cm})$ & $2(4.5-5.0 \mathrm{~cm})$ & $3(6.0-7.0 \mathrm{~cm})$ & $4(8.0-9.0 \mathrm{~cm})$ & $5(10.0-36.0 \mathrm{~cm})$ \\
\hline $\mathrm{N}$ & 37 & 25 & 51 & 27 & 37 \\
\hline Recurrence, n (\%) & 0 & $1(4.0)$ & $1(2.0)$ & $8(29.6)$ & $10(27.0)$ \\
\hline Unadjusted OR (95\% CI) & 1.00 & & $1.26(0.08-20.6)$ & $26.5(3.1-225.7)$ & $23.3(2.80-191.4)$ \\
\hline$P$ value & - & & .87 & .003 & .003 \\
\hline
\end{tabular}

Note the separation at $8 \mathrm{~cm}$ and beyond. The same result was seen when size was divided into deciles. OR, Odds ratio; $95 \% \mathrm{Cl}, 95 \%$ confidence interval. 


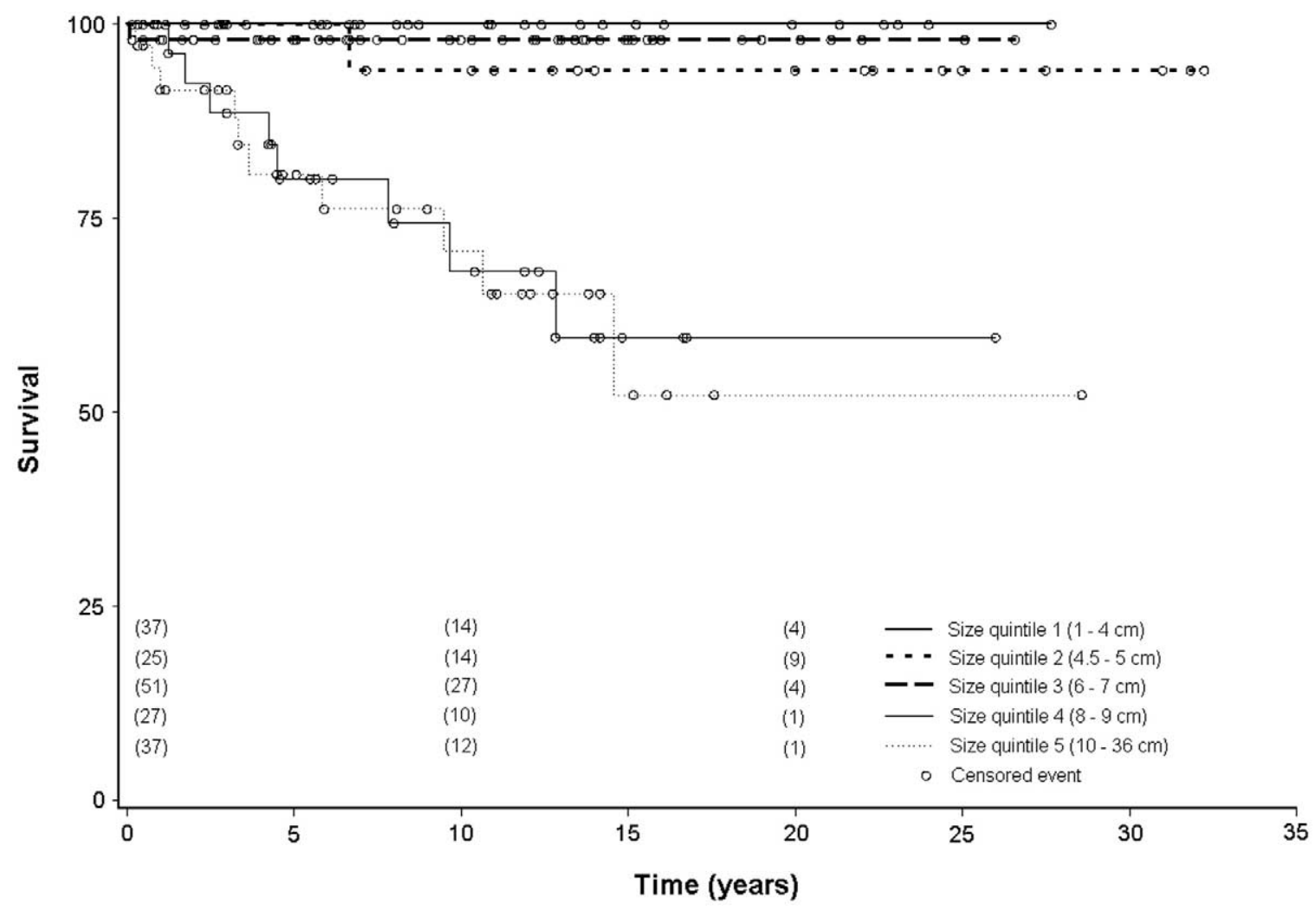

Figure 1. Kaplan-Meier estimate of recurrence as a function of size. Note the clear separation at $8 \mathrm{~cm}$. Number at risk at 0,10 , and 20 years for each stratum is given in parentheses.

characteristic curves were generated for the logistic models and are seen in Figure 4. The c statistic (area under the curve) was 0.92, and the Hosmer-Lemeshow test result was 0.95 when all 3 variables (stage, histology, and size) were in the model. Bootstrap analysis demonstrated that only Masaoka stage remained robust $(P<.0001)$ in predicting recurrence, whereas WHO histology $(P=.35)$ and size $(P=.15)$ did not. Multivariable models were also constructed to predict thymoma deaths. Size (OR, 1.09; $P<$ $.02)$, WHO histology (OR, 7.68; $P=.004)$, and Masaoka stage (OR, 4.54; $P=.002$ ) again were found to be significant in a Cox proportional hazards model. Patients who had postoperative radiation had a higher recurrence and death from thymoma rate (both $<.0001$ ), but this finding was not significant in the multivariable model. Because of the long time period of the study, the data set was divided into 2 time periods (before and after 1990) to examine the effects of the time period on results. Stage, histology, and size did not change significantly with time. There was no difference in recurrence rate between the 2 time periods.

\section{Discussion}

Masaoka stage was a strong independent predictor of thymoma recurrence, a result expected from a descriptor of invasion. However, there was no clinical difference between stages I and II, an observation shared by several recent reports. ${ }^{1,2,6,7,9,10}$ Because the objective of a staging scheme is to separate different groups of patients according to prognosis, the Masaoka system can be consolidated into 3 stages, combining stages I and II. No single invasion variable independently predicted recurrence, a finding explained by their inclusion into the Masaoka stage. Although some previous reports found great vessel invasion to be an independent predictor, our analysis does not. ${ }^{4}$ This is perhaps due to the small number of involved patients, the favorable response to adjuvant treatment, and the high correlation with the other invasion variables. Most reports indicate that complete resection is an independent risk factor. Complete resection was a strong univariable but not an independent predictor in our analysis. Again, we suspect the small number of patients with incomplete resection, a favorable response to adjuvant treatment, and confounding with the 3 multivariable predictors. There were too few patients who had induction therapy to ascertain the efficacy of preoperative treatment. The influence of adjuvant radiation on recurrence was not fully examined in this report, but 2 recent reports from our center suggest there is a questionable role for radiation in patients who have stage 2 or 3 


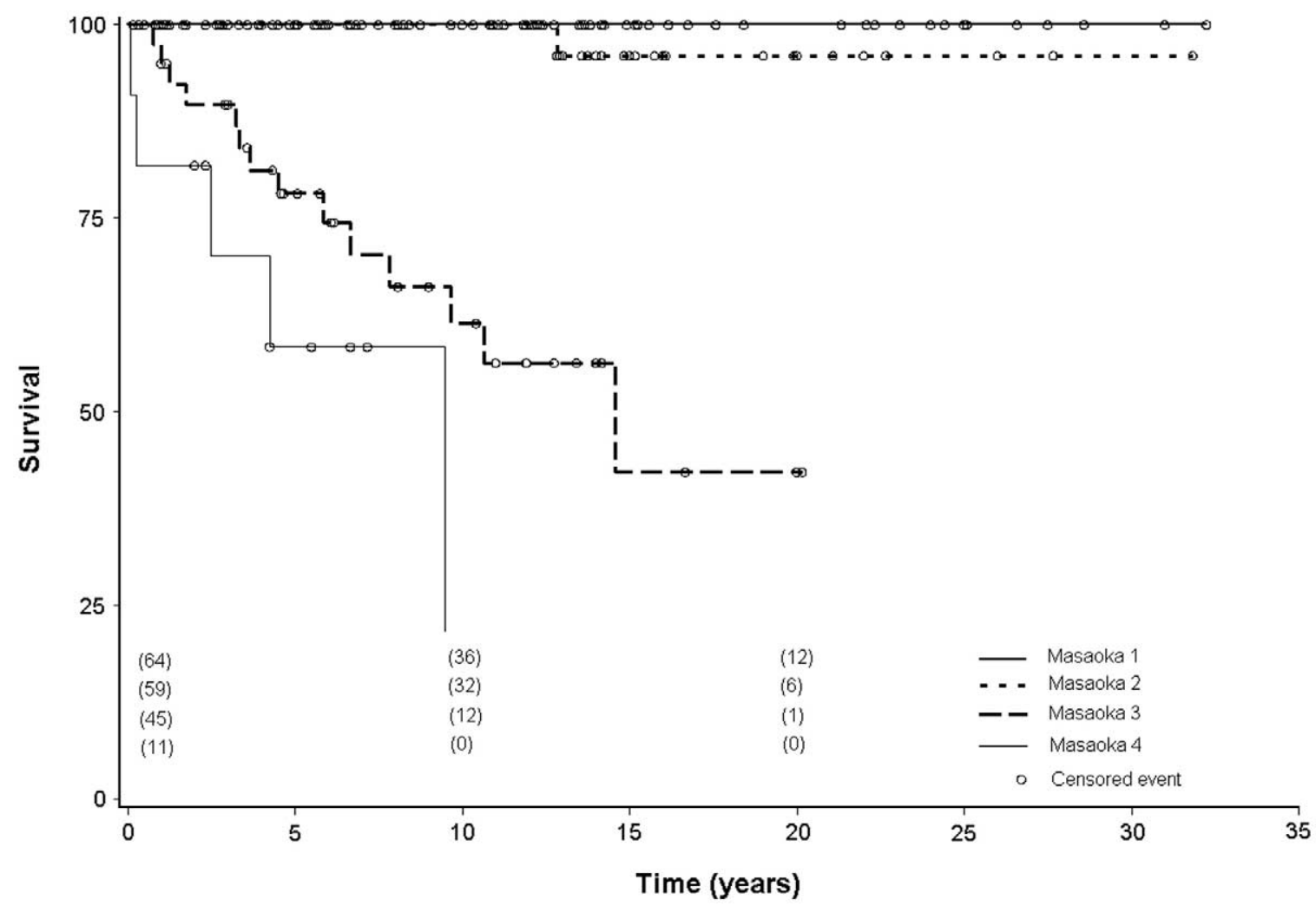

Figure 2. Kaplan-Meier estimate of recurrence as a function of Masaoka stage. Number at risk at 0 , 10, and 20 years for each stratum is given in parentheses.

tumors that are completely resected. ${ }^{14,15}$ Multivariable analysis demonstrated that adjuvant radiation was not a predictor of recurrence or death.

WHO histology was also an independent predictor of thymoma recurrence, which is not surprising because histology is strongly correlated with tumor invasiveness and thus Masaoka stage. Several recent reports concur with this observation and add support to consider WHO histology in estimating prognosis. ${ }^{1,2,5-10}$ Although there are 6 histologic types of thymic tumors, the clinical grouping of these tumors could probably be simplified for clinical use into 4 groups with a similar prognosis: $\mathrm{A}$ ( $\mathrm{A}$ and $\mathrm{AB})$, early $\mathrm{B}$ (B1 and B2), B3, and C. Type B3 and C tumors are very aggressive and essentially always require multimodality treatment. Two extremes of histology can serve as examples as to how treatment and prognosis might be refined. One example might be a patient with a Masaoka stage II tumor that is a type A. The prognosis should be excellent, with little chance adjuvant therapy would improve the result. Alternatively, a stage III type B3 tumor is at much greater risk of recurrence, the prognosis is more guarded, and multimodality therapy should be strongly considered.

Tumor size was an independent predictor of recurrence, and there is a threshold size that is clinically useful. Size is intuitively correlated with degree of invasion and worse histology. Indeed, that was the case in our data set, in which size of $8 \mathrm{~cm}$ or greater was associated with advanced stage and worse histology. Other studies have demonstrated that larger tumors have a worse prognosis but have not investigated the relationship in detail. ${ }^{3,7}$ Our findings suggest a threshold effect at $8 \mathrm{~cm}$, with a marked increase in recurrence compared with smaller tumors. This association persisted even when only Masaoka stage III tumors were considered. The relationship between size and prognosis could be clinically useful because it is the one variable that can be known for sure before resection to guide therapy.

TABLE 3. Recurrence rate as a function of Masaoka stage

\begin{tabular}{lcccc}
\hline Masaoka stage: & I & II & III & IV \\
\hline $\mathrm{N}$ & 64 & 59 & 45 & 11 \\
$\begin{array}{l}\text { Recurrence, } \\
\mathrm{n}(\%)\end{array}$ & 0 & $1(1.7)$ & $14(31.1)$ & $5(45.4)$ \\
$\begin{array}{c}\text { Unadjusted } 0 \mathrm{R} \\
\quad \text { (95\% CI) }\end{array}$ & 1.00 & & $55.1(7.0-434.8)$ & $101.6(10.2->999.9)$ \\
$\begin{array}{l}P \text { value } \\
\text { value }\end{array}$ & - & & .0001 & $<.0001$ \\
\hline
\end{tabular}

$O R$, Odds ratio; $95 \% \mathrm{Cl}, 95 \%$ confidence interval. 


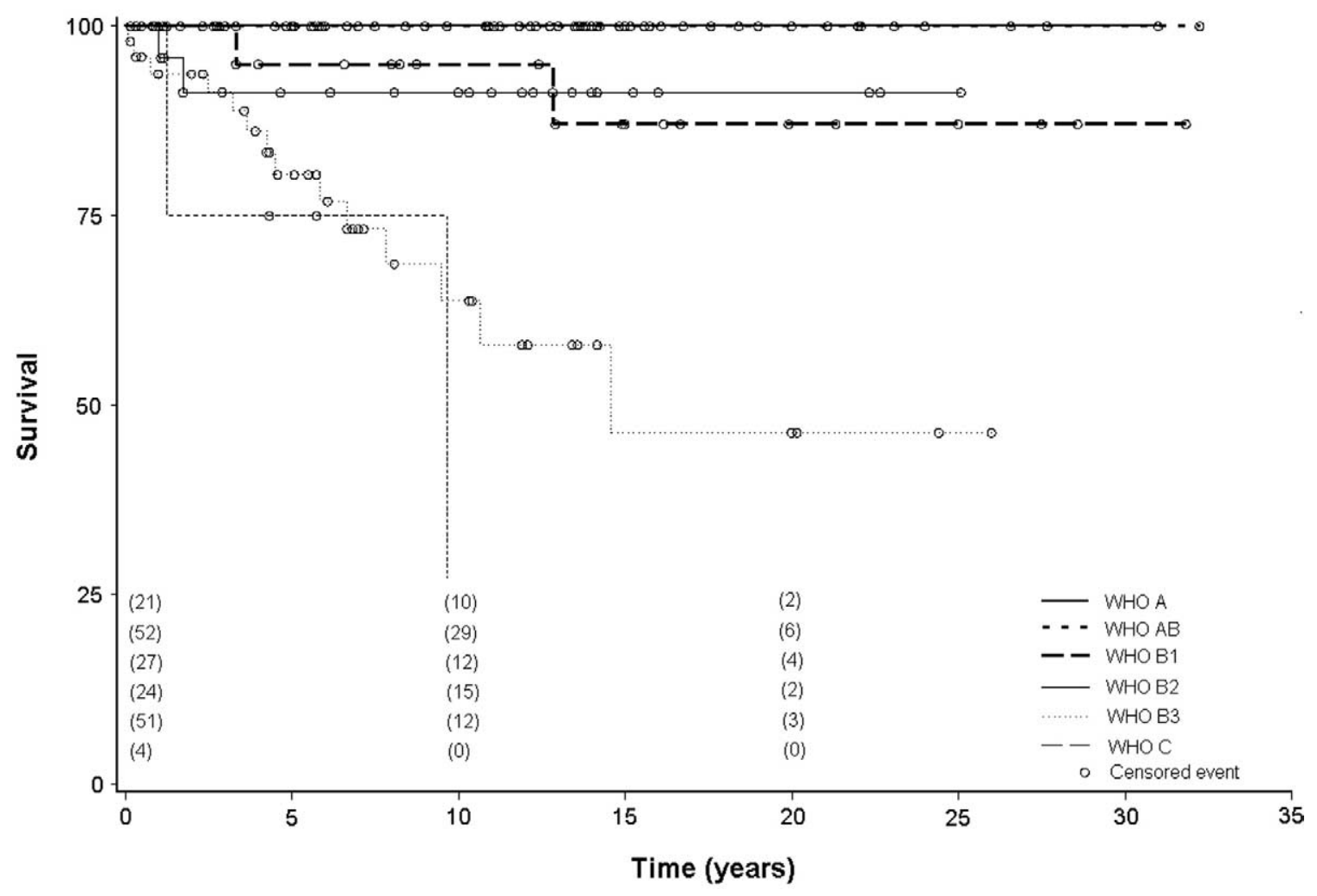

Figure 3. Kaplan-Meier estimate of recurrence as a function of World Health Organization (WHO) histology. Number at risk at 0,10 , and 20 years for each stratum is given in parentheses.

Masaoka stage is very difficult to assign before resection because invasion is difficult to differentiate from simple abutment on the computed tomographic scan. Because Masaoka stage assignment is unreliable before resection, another surrogate marker of poor prognosis would be helpful. Tumor size would be a good preoperative predictor because it is easily determined. Recent reports suggest a survival advantage to induction therapy of stage III thymomas, as opposed to adjuvant treatment. ${ }^{16-18}$ Tumors of less than $8 \mathrm{~cm}$ without evidence of invasion on computed tomography would be resected for both diagnosis and therapy. Tumors of $8 \mathrm{~cm}$ or larger (or those rare tumors $<8 \mathrm{~cm}$ that have evidence of invasion suggestive of stage III) would be candi- dates for induction therapy to be followed by resection. A core cutting biopsy would need to be performed before induction therapy, and this information could be further used to eliminate overtreatment of patients with good prognoses. The occasional large tumor that also happens to be a type $\mathrm{A}$ ( $\mathrm{A}$ or $\mathrm{AB}$ ) tumor could be spared induction therapy, whereas a type B or C tumor would proceed to induction therapy. The $\mathrm{c}$ statistic for this information (size and histology) is 0.90 , which is clinically very acceptable and close to c statistic of 0.92 for the full model with all 3 variables.

There are several limitations of our study. Death is a hard end point, but it is possible that a few patients who died of other causes also had an asymptomatic thymoma recurrence

TABLE 4. Recurrence rate as a function of WHO histology

\begin{tabular}{lcccccc}
\hline \multicolumn{1}{c}{ WHO histology: } & A & AB & B1 & B2 & B3 & C \\
\hline $\mathrm{N}$ & 21 & 52 & 27 & 24 & 51 & 4 \\
Recurrence, $\mathrm{n}(\%)$ & 0 & 0 & $2(7.4)$ & $2(8.3)$ & $4.4(27.4)$ & $2(50.0)$ \\
Unadjusted OR (95\% CI) & 1.00 & & & $.0 .60-33.4)$ & $18.5(4.0-85.5)$ & $49.0(4.4-544.8)$ \\
$P$ value & - & & & .15 & .0002 & .002 \\
\hline
\end{tabular}

$\mathrm{B} 1$ was combined with $\mathrm{A}$ and $\mathrm{AB}$ because there were no events for the latter two. WHO, World Health Organization; $0 \mathrm{R}$, odds ratio; $95 \% \mathrm{Cl}, 95 \%$ confidence interval. 


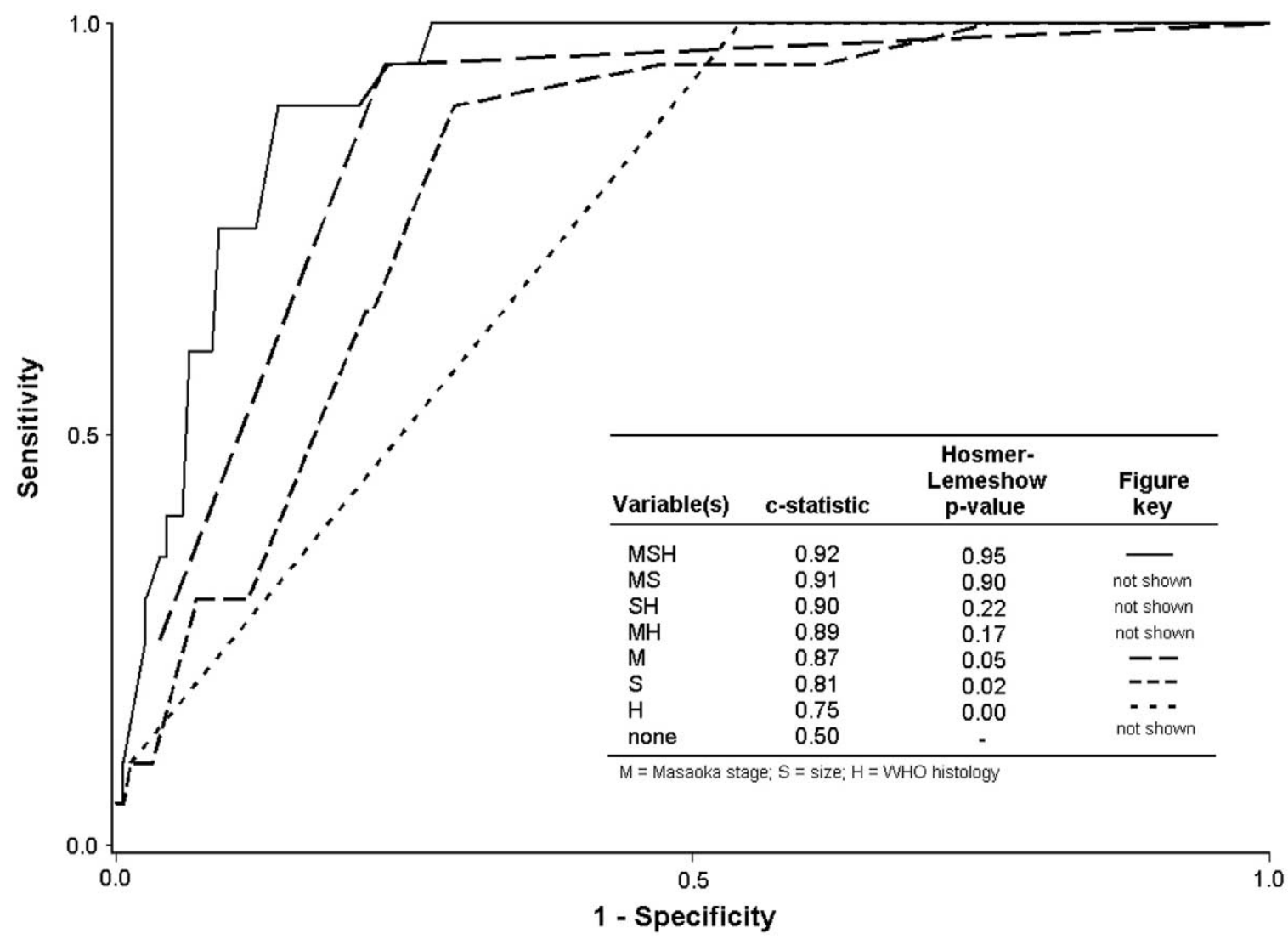

Figure 4. Receiver operating characteristic curves for logistic models of recurrence.

that was not suspected at the time of death. This could have artificially raised the recurrence-free survival. Not all patients were carefully followed beyond 5 years after resection, such that although they might have been asymptomatic when they were contacted for follow-up, they could have had an early recurrence that was not clinically manifest yet. This would artificially improve the recurrence rate and recurrence-free survival. This was a single-institution experience, and therefore this data set might not be readily applicable to all patients with thymic tumors. Our data set was weighted with low-risk patients with stage I and II tumors, which thus lowered the recurrence rate and hence our ability to robustly model recurrence. This was born out in our bootstrap analysis of the recurrence model, which only confirmed Masaoka stage and not size or histology in the model prediction. This result is not that surprising with only 179 patients and only 20 events in the data set. However, several other recent well-analyzed studies have also found these variables to be important, and therefore it is very likely these are clinically relevant.

Recurrences are uncommon after resection of a thymoma. Most deaths after thymoma resection are due to other causes than tumor recurrence. There was no important difference in recurrences or deaths between Masaoka stage I and II tumors, and therefore there is little value in separating these 2 similar groups of patients. Masaoka stage is highly correlated with WHO histology and size. The WHO histologic groups could be clinically simplified from 6 groupings to 4: A (A and AB), early B (B1 and B2), B3, and C. Tumors of $8 \mathrm{~cm}$ or larger have a significantly increased recurrence rate. A model containing the variables Masaoka stage, WHO histology, and size predicts recurrence in a reliable fashion. Size might be a valuable preoperative predictor to help decide which patients might benefit from induction therapy.

\section{References}

1. Pescarmona E, Rendina EA, Venuta F, Arcangelo ED, Pagani M, Ricci $\mathrm{C}$, et al. Analysis of prognostic factors and clinicopathological staging of thymoma. Ann Thorac Surg. 1990;50:534-8.

2. Quintanilla-Martinez L, Wilkins EW, Choi NC, Efird J, Hug E, Harris NL. Thymoma. Histologic subclassification is an independent prognostic factor. Cancer. 1994;74:606-17. 
3. Blumberg D, Port JL, Weksler B, Delgado R, Rosai J, Bains MS, et al. Thymoma: a multivariate analysis of factors predicting survival. Ann Thorac Surg. 1995;60:908-14.

4. Okumura M, Miyoshi S, Takeuchi Y, Yoon, HE, Minami M, Takeda SI, et al. Results of surgical treatment of thymomas with special reference to the involved organs. J Thorac Cardiovasc Surg. 1999; 117:605-13.

5. Lardinois D, Rechsteiner R, Lang RH, Gugger M, Betticher D, von Briel C, et al. Prognostic relevance of Masaoka and Muller-Hermelink classification in patients with thymic tumors. Ann Thorac Surg. 2000; 69:1550-5

6. Okumura M, Ohta M, Tateyama H, Nagawawa K, Matsumura A, Maeda H, et al. The World Health Organization classification system reflects the oncologic behavior of thymoma. Cancer. 2002;94:624-32.

7. Nakagawa K, Asamura H, Matsuno Y, Suzuki K, Kondo H, Maeshima $\mathrm{H}$, et al. Thymoma: a clinicopathologic study based on the new World Health Organization classification. J Thorac Cardiovasc Surg. 2003; 126:1134-40.

8. Monden Y, Kondo K. Therapy for thymic epithelial tumors: a clinical study of 1,320 patients from Japan. Ann Thorac Surg. 2003;76:878-85.

9. Park MS, Chung KY, Kim KD, Yang WI, Chung JH, Kim YS, et al. Prognosis of thymic epithelial tumors according to the new World Health Organization histologic classification. Ann Thorac Surg. 2004; 78:992-8.

10. Kondo K, Yoshizawa K, Tsuyuguchi M, Kimura S, Sumitomo M, Morita J, et al. WHO histologic classification is a prognostic indicator in thymoma. Ann Thorac Surg. 2004;77:1183-8.

11. Berg NP, Gatzinsky P, Larsson S, Lundin P, Ridell B. Tumors of the thymus and thymic region: clinicopathological studies on thymomas. Ann Thorac Surg. 1978:25:91-8.

12. Gamondes JP, Balawi A, Greenland T, Adleine P, Morney JF, Zhang $\mathrm{J}$, et al. Seventeen years of surgical treatment of thymoma: factors influencing survival. Eur J Cardiothoracic Surg. 1991;5:124-31.

13. Masaoka A, Monden Y, Nakahara K, Tanioka T. Follow-up study of thymomas with special reference to their clinical stages. Cancer. 1981;48:2485-92.

14. Mangi AA, Wain JC, Donahue DM, Grillo HC, Mathisen DJ, Wright CD. Adjuvant radiation of stage III thymoma: is it necessary? Ann Thorac Surg. 2005;79:1834-9.

15. Mangi AA, Wright CD, Allan JS, Wain JC, Donahue DM, Grillo HC, et al. Adjuvant radiation therapy for stage II thymoma. Ann Thorac Surg. 2002;74:1033-7.

16. Rea F, Satori F, Loy M, Calabro F, Fornasiero A, Daniele O, et al. Chemotherapy and operation for invasive thymoma. $J$ Thorac Cardiovasc Surg. 1993;106:543-9.

17. Venuta F, Rendina EA, Pescarmona EO, De Giacomo T, Vegna ML, Fazi P, et al. Multimodality treatment of thymoma: a prospective study. Ann Thorac Surg. 1997;64:1585-92.

18. Venuta F, Rendina EA, Longo F, De Giacomo T, Anile M, Mercadante $\mathrm{E}$, et al. Long-term outcome after multimodality treatment for stage III thymic tumors. Ann Thorac Surg. 2003;76:1866-72.

\section{Discussion}

Dr Frank C. Detterbeck (Chapel Hill, NC). I compliment you on a nice study.

I think there are several aspects of this article that really deserve some emphasis. First is the consideration of the end points. I certainly agree wholeheartedly that overall survival is a poor end point in studies regarding thymoma, and we really need to be looking at recurrence or disease-free survival. Second, the need for prolonged follow-up, as you have in your study, is critically important. I think these are major aspects that need to be emphasized.

Another important aspect is that you have attempted to arrive at insights that can guide us in the management of future patients. Certainly the study has analyzed features that are available postoperatively, such as the Masaoka stage or the WHO histologic subtype, but I compliment you for trying to take this a step further and using what we can get from this to try to guide us with regard to patients we see preoperatively. This is particularly important because I think there are more and more compelling data, including from your own institution, that preoperative chemotherapy for high-risk patients is beneficial.

Certainly one of the characteristics, as you pointed out, was that size was a marker of poor outcomes, and that is easy to assess preoperatively, or at least we are pretty comfortable that we can assess it accurately preoperatively. However, I do think a word of caution is warranted. Of 6 larger series of thymomas in which the prognostic value of size was assessed by means of multivariate analysis, 3 found this to be an independent predictor and 3 did not with regard to overall survival. With regard to recurrence, this study is the only one that demonstrated significance to size, whereas 3 others, including an earlier one from Massachusetts General Hospital, did not.

Masaoka stage has certainly been found to be an independent predictor of survival in really every multivariate analysis that has assessed this. The problem is that no study has really analyzed how reliable a preoperative scan is in determining the actual Masaoka stage. The clinical impression that many of us have is that it is difficult to differentiate abutment versus actual invasion. Therefore one of my questions, Dr Wright, is whether you have any data regarding how reliable the preoperative assessment of stage was compared with what was actually found.

Dr Wright. We actually did not assign a stage preoperatively to these patients. As you say, the Masaoka system is a surgical staging system, and therefore it is a postoperative value. Obviously, clinical intuition is used to estimate whether a complete resection can be done (ie, stage I or II), but we did not assign that value preoperatively.

Dr Detterbeck. The third factor of significance in your study is the WHO histologic classification. I am personally still struggling to understand the exact value of this classification and how best to use it. Previous systems were rather inconsistent between different pathologists, and in general, the multivariate analyses did not suggest independent significance. Now 5 of 8 studies, including this one, that have looked at the value of the WHO system and Masaoka stage have found it to be prognostically significant. However, in looking at the details of these studies, the most consistent message is that type $\mathrm{C}$ has a poor prognosis, a minority of studies have suggested that type B3 is intermediate, and the results for the other types $(\mathrm{A}, \mathrm{AB}, \mathrm{B} 1$, and $\mathrm{B} 2)$ are rather inconsistent among studies. You have suggested that $\mathrm{A}$ and $\mathrm{AB}$ are better than B1 and B2, but other studies have really not found that.

It might be that the histologic heterogeneity of tumors is a problem. There was a study by Moran and Suster that suggested that you needed to have at least 5 slides examined to be able to accurately assess that. Therefore how many slides did you look at to assess the stage or the histologic subtype?

Dr Wright. Well, I cannot answer that question. But as you are probably aware, Nancy Harris is our director of surgical pathology, and she is an expert on thymoma. She had Professor MullerHermelink come over to our institution to educate our pathologists on how to use his classification system, and all of the slides were reviewed by Professor Muller-Hermelink. Every thymoma case is 
signed out by 2 pathologists. Therefore I think they are pretty good, but I am not a pathologist.

Dr Detterbeck. I think the biggest problem is our ability to determine the subtype preoperatively. Do you have any data regarding how often a preoperative core-needle biopsy actually correlated with the histologic subtype in an actual resection specimen?

Dr Wright. I do not have that actual information. There is no question that there is a potential bias of sampling error the smaller the biopsy is in thymomas, and that can be a potentially major clinical problem that definitely confounds proper histologic typing of tumors preoperatively.

Dr Detterbeck. Finally, how should we actually use the histologic classification? Most of the data for chemotherapy have really involved preoperative chemotherapy. Are we really justified in using histologic subtype to guide us with regard to postoperative adjuvant therapy? What do you think?

Dr Wright. Well, I think the extremes can be helpful, and the middle is a hard ground.

Some type A tumors can be quite big, you know, well over $10 \mathrm{~cm}$. That is one of the anomalies of our particular data set, and this has been noticed by other authors. But if I have an A tumor and I know about it either preoperatively or postoperatively, I know that they are clinically benign and rarely recur, and I would not give that patient induction or adjuvant therapy. If I had a large B3 tumor, I would recommend induction therapy because they have a high chance of recurrence.

Dr Federico Venuta (Rome, Italy). Congratulations on your study.

This is a retrospective study, and you started to evaluate the results with patients who were operated on more than 30 years ago. I am sure you changed your policy at least a little in this period of time according to the indications for postoperative chemotherapy and radiotherapy and induction chemotherapy. How did you change your policy in this period of time? Did you try to stratify your results according to the time when the operation was done?

Dr Wright. We stratified our results in half and looked at the early versus late global results, and there was no difference in recurrence rate or death rate caused by thymoma. In the last 5 years or so, we have increasingly started with induction chemotherapy or chemoradiotherapy for patients who we think, as you do, are poorly resectable, but that is a relatively small number of patients. As you know, we have published several series now looking at the influence of adjuvant radiation therapy, and there seems to be no meaningful improvement in recurrence or disease-free survival with postoperative adjuvant radiotherapy, and that was not a univariate or a multivariate predictor of recurrence. I applaud your results, Dr Venuta, of the prospective treatment of these patients, and that is what I think we need to move to. I am suggesting that $8 \mathrm{~cm}$ might be a reasonable way to start.

Dr David J. Sugarbaker (Boston, Mass). Because you have really extensive experience with this problem, could you comment on lymph node involvement and its effect on survival?

Dr Wright. Well, there was a TNM system proposed by one of our Japanese colleagues several years ago in thymoma, but the problem was that there were so few patients who had lymph nodes involved. In our experience it is only the B3 tumors or C tumors that had lymph nodes involved, and therefore it was not clinically useful in terms of stratification. In thymic carcinoma it is an important prognostic factor.

Dr Sugarbaker. Therefore if you find it, you can consider it sort of incidental, and, in your well-studied opinion, both clinically and from the literature, it is just not that important here?

Dr Wright. Yes, that is true for thymoma. 